Giovanni Volpicelli

Mahmoud Elbarbary

Michael Blaivas

Daniel A. Lichtenstein

Gebhard Mathis

Andrew W. Kirkpatrick

Lawrence Melniker

Luna Gargani

Vicki E. Noble

Gabriele Via

Anthony Dean

James W. Tsung

Gino Soldati

Roberto Copetti

Belaid Bouhemad

Angelika Reissig

Eustachio Agricola

Jean-Jacques Rouby

Charlotte Arbelot

Andrew Liteplo

Ashot Sargsyan

Fernando Silva

Richard Hoppmann

Raoul Breitkreutz

Armin Seibel

Luca Neri

Enrico Storti

Tomislav Petrovic

International Liaison Committee on Lung Ultrasound

(ILC-LUS) for the International

Consensus Conference on Lung Ultrasound (ICC-LUS)

Received: 29 October 2011

Accepted: 23 January 2012

Published online: 6 March 2012

(C) Copyright jointly held by Springer and ESICM 2012

Electronic supplementary material

The online version of this article

(doi:10.1007/s00134-012-2513-4) contains

supplementary material, which is available to authorized users.

G. Volpicelli $(\bowtie)$

Department of Emergency Medicine,

San Luigi Gonzaga University Hospital,

10043 Orbassano, Torino, Italy

e-mail: gio.volpicelli@tin.it

M. Elbarbary

National \& Gulf Center for Evidence Based

Health Practice, King Saud University for

Health Sciences, Riyadh, Saudi Arabia

e-mail: mahmoud_barbary@yahoo.com

\title{
International evidence-based recommendations for point-of-care lung ultrasound
}

L. Melniker

Clinical Epidemiology Unit, Division of General Internal Medicine, Department of Medicine, Weill Medical College of Cornell University, New York, USA

e-mail: lawrence.melniker@winfocus.org

L. Gargani

Institute of Clinical Physiology, National Research Council, Pisa, Italy e-mail: gargani@ifc.cnr.it

\section{E. Noble}

\section{G. Mathis}

Internal Medicine Praxis, Rankweil, Austria e-mail: gebhard.mathis@cable.vol.at
A. W. Kirkpatrick
Foothills Medical Centre, Calgary, AB,
Canada
e-mail: andrew.kirkpatrick@ albertahealthservices.ca

Division of Emergency Ultrasound, Department of Emergency Medicine, Massachusetts General Hospital, Boston, MA, USA e-mail: vnoble@partners.org

G. Via

1st Department of Anesthesia and Intensive Care Pavia, IRCCS Foundation Policlinico San Matteo, Pavia, Italy e-mail: gabriele.via@winfocus.org 


\section{A. Dean}

Division of Emergency Ultrasonography,

Department of Emergency Medicine,

University of Pennsylvania Medical Center,

Philadelphia, PA, USA

e-mail: anthony.dean@uphs.upenn.edu

J. W. Tsung

Departments of Emergency Medicine and Pediatrics, Mount Sinai School of Medicine, New York, NY, USA

e-mail: jtsung@gmail.com

\section{G. Soldati}

Emergency Medicine Unit, Valle del Serchio General Hospital, Lucca, Italy e-mail: g.soldati@usl2.toscana.it

R. Copetti

Medical Department, Latisana Hospital, Udine, Italy

e-mail: robcopet@tin.it

B. Bouhemad

Surgical Intensive Care Unit, Department of Anesthesia and Critical Care, Groupe Hospitalier Paris Saint-Joseph, Paris, France e-mail: belaid_bouhemad@hotmail.com

A. Reissig

Department of Pneumology and Allergology, Medical University Clinic I, Friedrich-Schiller University, Jena, Germany

e-mail: Angelika.Reissig@med.uni-jena.de

E. Agricola

Division of Noninvasive Cardiology,

San Raffaele Scientific Institute, IRCCS,

Milan, Italy

e-mail: agricola.eustachio@hsr.it

\section{J.-J. Rouby · C. Arbelot}

Multidisciplinary Intensive Care Unit, Department of Anesthesiology,

Pitié-Salpêtrière Hospital,

University Pierre and Marie Curie (UPMC),

Paris 6, France

e-mail: jjrouby@invivo.edu

C. Arbelot

e-mail: charlotte.arbelot@psl.aphp.fr

A. Liteplo

Emergency Medicine, Massachusetts

General Hospital, Boston, MA, USA

e-mail: aliteplo@partners.org

\section{A. Sargsyan}

Wyle/NASA Lyndon B. Johnson Space

Center Bioastronautics Contract,

Houston, TX, USA

e-mail: ashot.sargsyan@nasa.gov
F. Silva

Department of Emergency Medicine,

UC Davis Medical Center,

Sacramento, CA, USA

e-mail: fernando.silva@winfocus.org

\section{R. Hoppmann}

Internal Medicine, University of South

Carolina School of Medicine,

Columbia, SC, USA

e-mail: Richard.hoppmann@uscmed.sc.edu

\section{R. Breitkreutz}

Department of Anaesthesiology, Intensive Care and Pain Therapy, University Hospital of the Saarland and Frankfurt Institute of Emergency Medicine and Simulation Training (FINEST), Homburg, Germany e-mail: raoul.breitkreutz@gmail.com

\section{A. Seibel}

Diakonie Klinikum jung-stilling,

Siegen, Germany

e-mail: arminseibel1@hotmail.com

L. Neri

AREU EMS Public Regional Company, Niguarda Ca' Granda Hospital, Milano, Italy

e-mail: luca.neri@winfocus.org

\section{E. Storti}

Intensive Care Unit "G. Bozza,", Niguarda Ca' Granda Hospital, Milan, Italy

e-mail: enrico.storti@winfocus.org

\section{T. Petrovic}

Samu 93, University Hospital Avicenne, Bobigny, France

e-mail: tomislav.petrovic@winfocus.org

Abstract Background: The purpose of this study is to provide evidence-based and expert consensus recommendations for lung ultrasound with focus on emergency and critical care settings. Methods: A multidisciplinary panel of 28 experts from eight countries was involved. Literature was reviewed from January 1966 to June 2011. Consensus members searched multiple databases including Pubmed, Medline, OVID, Embase, and others. The process used to develop these evidence-based recommendations involved two phases: determining the level of quality of evidence and developing the recommendation. The quality of evidence is assessed by the grading of recommendation, assessment, development, and evaluation (GRADE) method. However, the GRADE system does not enforce a specific method on how the panel should reach decisions during the consensus process. Our methodology committee decided to utilize the RAND appropriateness method for panel judgment and decisions/consensus. Results: Seventythree proposed statements were examined and discussed in three conferences held in Bologna, Pisa, and Rome. Each conference included two rounds of face-to-face modified Delphi technique. Anonymous panel voting followed each round. The panel did not reach an agreement and therefore did not adopt any recommendations for six statements. Weak/ conditional recommendations were made for 2 statements, and strong recommendations were made for the remaining 65 statements. The statements were then recategorized and grouped to their current format. Internal and external peer-review processes took place before submission of the recommendations. Updates will occur at least every 4 years or whenever significant major changes in evidence appear. Conclusions: This document reflects the overall results of the first consensus conference on "point-of-care" lung ultrasound. Statements were discussed and elaborated by experts who published the vast majority of papers on clinical use of lung ultrasound in the last 20 years. Recommendations were produced to guide implementation, development, and standardization of lung ultrasound in all relevant settings.

Keywords Lung ultrasound .

Chest sonography · Emergency ultrasound - Critical ultrasound . Point-of-care ultrasound - Guideline . RAND - GRADE .

Evidence-based medicine 


\section{Introduction}

Modern lung ultrasound is mainly applied not only in critical care, emergency medicine, and trauma surgery, but also in pulmonary and internal medicine. Many international authors have produced several studies on the application of lung ultrasound in various settings. The emergence of differences in approach, techniques utilized, and nomenclature, however, provided the stimulus to initiate a guideline/consensus process with the aim of elaborating a unified approach and language for six major areas, namely terminology, technology, technique, clinical outcomes, cost effectiveness, and future research. This process was conducted following a rigorous scientific pathway to produce evidence-based guidelines containing a list of recommendations for clinical application of lung ultrasound [1]. A literature search was performed, and a multidisciplinary, international panel of experts was identified. The proposed recommendations represent a framework for "point-ofcare" lung ultrasound intended to standardize its application around the globe and in different clinical settings.

This report constitutes a concise, shortened version of the original document. The electronic version, accessible online as supplementary material, provides a full explanation of methods and a comprehensive discussion for each recommendation (see Electronic Supplementary Material 1).

\section{Methods}

Grading of recommendation, assessment, development, and evaluation (GRADE) method was used to develop these evidence-based recommendations [2]. The process involves two phases: (1) determining the level of quality of evidence, and (2) developing the recommendation. Relevant articles with clinical outcomes were classified into three levels of quality based on the criteria of the GRADE methodology for developing guidelines and clinical recommendations (Table 1). RAND appropriateness method (RAM) was used within the GRADE steps that required panel judgment and decisions/consensus [3]. RAM was also used in formulating the recommendations based purely on expert consensus, such as recommendations related to terminology. Recommendations were generated in two classes (strong or weak/conditional) based on the GRADE criteria taking into consideration preset rules that defined the panel agreement/consensus and its degree. The transformation of evidence into recommendation depends on the evaluation by the panel for outcome, benefit/cost, and benefit/harm ratios, and certainty about similarity in values/preferences [2].
Table 1 Levels of quality of evidence

\begin{tabular}{llll}
\hline Level & Points $^{\text {b }}$ & Quality & Interpretation \\
\hline A & $\geq 4$ & High & $\begin{array}{l}\text { Further research is very unlikely to } \\
\text { change our confidence in the estimate } \\
\text { of effect or accuracy }\end{array}$ \\
$C^{\text {a }}$ & 3 & Moderate & $\begin{array}{l}\text { Further research is likely to have an } \\
\text { important impact on our confidence in } \\
\text { the estimate of effect or accuracy and } \\
\text { may change the estimate } \\
\text { Further research is very likely to have } \\
\text { an important impact on our } \\
\text { confidence in the estimate of effect or } \\
\text { accuracy and is likely to change the } \\
\text { estimate. Any estimate of effect or } \\
\text { accuracy is very uncertain (very low) }\end{array}$ \\
\hline
\end{tabular}

This table was modified from Guyatt et al. [2]

${ }^{a}$ Level $\mathrm{C}$ can be divided into low (points $=2$ ) and very low (points $=1$ or less)

b Points are calculated based on the nine GRADE quality factors [2]

\section{Panel selection}

Experts were eligible for selection if they had published as first author a peer-reviewed article on lung ultrasound during the past 10 years in more than one main topic of lung ultrasound (pneumothorax, interstitial syndrome, lung consolidation, monitoring, neonatology, pleural effusion), taking into consideration the proportionality as determined by a MEDLINE literature search from 1966 to October 2010. Methodologists with experience in evidence-based methodology and guideline development were also included (see "Appendix" for list of participants, affiliations, and assignments).

\section{Literature search strategy}

The literature search was done in two tracks. The experts themselves, with more than one expert search in each domain to avoid selection bias, constituted the first track. An epidemiologist assisted by a professional librarian performed the second track by conducting literature search of English-language articles from 1966 to October 2010. See Table 2 for search databases, terms, and the MeSH headings used. The two bibliographies were compared for thoroughness and consistency.

\section{Panel meetings and voting}

The panel of experts met on three occasions: Bologna (28-30 November 2009), Pisa (11-12 May 2010), and Rome (7-9 October 2010). The panelists formulated draft 
Table 2 Search terms used

\begin{tabular}{|c|c|}
\hline $\begin{array}{l}\text { MeSH } \\
\text { headings }\end{array}$ & Terms \\
\hline Sonography & $\begin{array}{l}\text { (echographic OR echography OR sonographic OR } \\
\text { sonography OR ultrasonic OR ultrasonographic } \\
\text { OR ultrasonography OR ultrasound).ti }\end{array}$ \\
\hline EM/CCM & $\begin{array}{l}\text { (bedside OR critical OR intensive OR emergency OR } \\
\text { emergent OR urgency OR urgent OR critical OR } \\
\text { critically OR shock OR unstable OR hypotensive } \\
\text { OR hypoperfusion OR sepsis).ti }\end{array}$ \\
\hline ECHO & $\begin{array}{l}\text { (cardiac OR cardiologic OR cardiological } \\
\text { echocardiography OR echocardiographic OR heart } \\
\text { OR pacing OR chest OR lung OR congestive heart } \\
\text { failure OR CHF OR ADHF OR pressure).ti }\end{array}$ \\
\hline LUNG & $\begin{array}{l}\text { (lung OR chest OR thoracic OR transthoracic OR } \\
\text { cardiothoracic OR pleural OR pulmonary OR } \\
\text { pulmonic OR pneumology OR pneumonic OR } \\
\text { alveolar OR interstitial OR pneumothorax OR } \\
\text { hemothorax OR consolidation).ti }\end{array}$ \\
\hline OTHER & $\begin{array}{l}\text { (accuracy OR accurate OR sensitivity OR sensitive } \\
\text { OR specificity OR specific OR predictive OR } \\
\text { predict).ti }\end{array}$ \\
\hline COST & $\begin{array}{l}\text { (cost OR effective OR effectiveness OR efficacy OR } \\
\text { efficacious OR efficient OR efficiency OR benefit } \\
\text { OR value).ti }\end{array}$ \\
\hline
\end{tabular}

Search databases: Books@ Ovid June 02, 2011; Journals@ Ovid Full Text June 2003, 2011; Your Journals@Ovid; AMED (Allied and Comp Medicine) 1985 to May 2011; CAB Abstracts Archive 1910-1972; Embase 1980-2011 week 22; ERIC 1965 to May 2011; Health and Psychosocial Instruments 1985 to April 2011; Ovid MEDLINE(R) In-Process and Other Non-Indexed Citations and Ovid MEDLINE(R) 1948 to present; Ovid MEDLINE(R) 1948 to May week 4 2011; Social Work Abstracts 1968 to June 2011; NASW Clinical Register 14th Edition

recommendations before the conferences, which laid the foundation to work together and critique the recommendations during the conferences. At each plenary conference, a representative of each domain presented potentially controversial issues in the recommendations. A face-to-face debate took place in two rounds of modified Delphi technique; after each round, anonymous voting was conducted. A standardized method for determining the agreement/disagreement and the degree of agreement and hence for deciding about the grade of recommendation (weak versus strong) was then applied [3, 4].

\section{Results}

Literature search results

A total of 209 articles and two books were retrieved by the first track search. An additional 110 articles were added from the second track over a 1-year period. These 320 references (see Electronic Supplementary Material 1) were individually appraised based on methodological criteria to determine the initial quality level. The final judgment about the quality of evidence-based recommendations was only done after assigning the articles to each statement/question.

\section{General results}

A total number of 73 proposed statements were examined by 28 experts and discussed in the three conferences. Each statement was coded with an alphanumeric code, which includes the following in order of appearance: the location of the conference (Bologna, B; Pisa, P; Rome, $\mathrm{RL}$ ), the number assigned to the domain, and the number assigned to the statement. Table 3 presents each statement code with its grade of recommendation, degree of consensus, and level of quality of evidence.

\section{Statements and discussion}

Pneumothorax

\section{Technique}

Statement code B-D1-S1 (strong recommendation: level A of evidence)

- The sonographic signs of pneumothorax include the following:

- Presence of lung point(s)

- Absence of lung sliding

- Absence of B-lines

- Absence of lung pulse

B-D1-S2 (strong: level A)

- In the supine patient, the sonographic technique consists of exploration of the least gravitationally dependent areas progressing more laterally.

- Adjunct techniques such as M-mode and color Doppler may be used.

B-D1-S3 (weak: level C)

- Ultrasound scanning for pneumothorax may be a basic ultrasound technique with a steep learning curve.

P-D1-S2 (strong: level B)

- During assessment for pneumothorax in adults, a microconvex probe is preferred. However, other transducer (e.g., linear array, phased array, convex) may be chosen based on physician preference and clinical setting.

\section{Clinical implications}

\section{B-D1-S4 (strong: level A)}

- Lung ultrasound should be used in clinical settings when pneumothorax is in the differential diagnosis. 
Table 3 Summary table for the 73 statements with their level of evidence

\begin{tabular}{|c|c|c|c|c|c|c|c|c|c|}
\hline SN & $\begin{array}{l}\text { Statement } \\
\text { code }\end{array}$ & $\begin{array}{l}\text { Recommendation } \\
\text { strength }\end{array}$ & $\begin{array}{l}\text { Degree of } \\
\text { consensus }\end{array}$ & $\begin{array}{l}\text { Level of quality } \\
\text { of evidence }\end{array}$ & SN & $\begin{array}{l}\text { Statement } \\
\text { code }\end{array}$ & $\begin{array}{l}\text { Recommendation } \\
\text { strength }\end{array}$ & $\begin{array}{l}\text { Degree of } \\
\text { consensus }\end{array}$ & $\begin{array}{l}\text { Level of quality } \\
\text { of evidence }\end{array}$ \\
\hline 1 & B-D1-S1 & Strong & Very good & A & 38 & P-D2-S1 & Strong & Very good & N/A \\
\hline 2 & B-D1-S2 & Strong & Very good & A & 39 & P-D2-S2 & Strong & Very good & B \\
\hline 3 & B-D1-S3 & Weak & Some & $\mathrm{C}$ & 40 & P-D2-S3 & Strong & Very good & B \\
\hline 4 & B-D1-S4 & Strong & Very good & A & 41 & P-D2-S4 & No $=$ disagreement & No & $\mathrm{C}$ \\
\hline 5 & B-D1-S5 & Strong & Very good & B & 42 & P-D3-S1 & Strong & Very good & A \\
\hline 6 & B-D1-S6 & Strong & Good & A & 43 & P-D3-S2 & Strong & Very good & A \\
\hline 7 & B-D1-S7 & Strong & Good & $\mathrm{C}$ & 44 & P-D3-S3 & Strong & Very good & B \\
\hline 8 & B-D1-S8 & No $=$ disagreement & No & $\mathrm{C}$ & 45 & P-D3-S4 & Strong & Very good & B \\
\hline 9 & B-D2-S1 & Strong & Very good & A & 46 & P-D3-S5 & Strong & Very good & B \\
\hline 10 & B-D2-S2 & Strong & Very good & A & 47 & P-D3-S6 & Strong & Very good & B \\
\hline 11 & B-D2-S3 & Strong & Very good & B & 48 & P-D3-S7 & Strong & Very good & A \\
\hline 12 & B-D2-S4 & Strong & Good & B & 49 & P-D4-S1 & Strong & Very good & B \\
\hline 13 & B-D2-S5 & Strong & Very good & B & 50 & P-D4-S2 & Strong & Very good & B \\
\hline 14 & B-D2-S6 & Strong & Very good & B & 51 & P-D4-S3 & Strong & Very good & B \\
\hline 15 & B-D2-S7 & No $=$ disagreement & No & $\mathrm{C}$ & 52 & P-D4-S4 & Strong & Very good & B \\
\hline 16 & B-D2-S8 & Strong & Very good & $\mathrm{C}$ & 53 & P-D4-S5 & Strong & Very good & B \\
\hline 17 & B-D2-S9 & Strong & Very good & N/A & 54 & P-D4-S6 & Strong & Very good & B \\
\hline 18 & B-D2-S10 & Strong & Very good & N/A & 55 & P-D4-S7 & Strong & Very good & B \\
\hline 19 & B-D3-S1 & Strong & Very good & $\mathrm{C}$ & 56 & P-D4-S8 & Strong & Very good & A \\
\hline 20 & B-D3-S2 & Weak & Some & $\mathrm{C}$ & 57 & P-D4-S9 & Strong & Very good & A \\
\hline 21 & B-D3-S3 & Strong & Good & N/A & 58 & P-D5-S1 & Strong & Very good & B \\
\hline 22 & B-D3-S4 & Strong & Very good & A & 59 & RL-D2-S1 & Strong & Very good & A \\
\hline 23 & B-D3-S5 & Strong & Very good & A & 60 & RL-D2-S2 & Strong & Very good & A \\
\hline 24 & B-D3-S6 & Strong & Good & B & 61 & RL-D3-S1 & Strong & Very good & B \\
\hline 25 & B-D3-S7 & No $=$ disagreement & No & $\mathrm{C}$ & 62 & RL-D3-S2 & Strong & Very good & B \\
\hline 26 & B-D3-S8 & Strong & Very good & A & 63 & RL-D3-S3 & Strong & Very good & B \\
\hline 27 & B-D4-S1 & Strong & Good & A & 64 & RL-D3-S4 & Strong & Very good & B \\
\hline 28 & B-D4-S2 & Strong & Very good & A & 65 & RL-D3-S5 & Strong & Very good & B \\
\hline 29 & B-D4-S3 & Strong & Very good & A & 66 & RL-D4-S1 & Strong & Very good & B \\
\hline 30 & B-D4-S4 & Strong & Very good & A & 67 & RL-D4-S2 & Strong & Very good & B \\
\hline 31 & B-D4-S5 & Strong & Very good & B & 68 & RL-D4-S3 & Strong & Very good & A \\
\hline 32 & B-D4-S6 & Strong & Very good & B & 69 & RL-D4-S4 & Strong & Very good & A \\
\hline 33 & B-D4-S7 & Strong & Very good & A & 70 & RL-D4-S5 & Strong & Very good & A \\
\hline 34 & B-D4-S8 & Strong & Good & C & 71 & RL-D5-S1 & Strong & Very good & N/A \\
\hline 35 & B-D4-S9 & No $=$ disagreement & No & N/A & 72 & RL-D5-S2 & Strong & Very good & N/A \\
\hline 36 & P-D1-S1 & No $=$ disagreement & No & $\mathrm{C}$ & 73 & RL-D6-S1 & Strong & Good & B \\
\hline 37 & P-D1-S2 & Strong & Very good & B & & & & & \\
\hline
\end{tabular}

No statement for D1 in Rome (removed for duplication); RL-D6-S1 was a revision of P-D2-S4 due to new evidence presented; statement B-D3-S1 covers information given by statements P-D3-S4 and P-D3-S5; these latter two are not presented in the document

$B$ Bologna, $P$ Pisa, $R L$ Rome-Lung, $D$ domain, $S$ statement, $S N$ statement number, $N / A$ not applicable

\section{Imaging strategies and outcomes}

B-D1-S5 (strong: level B)

- Lung ultrasound more accurately rules in the diagnosis of pneumothorax than supine anterior chest radiography (CXR).

\section{B-D1-S6 (strong: level A)}

- Lung ultrasound more accurately rules out the diagnosis of pneumothorax than supine anterior chest radiography.

\section{B-D1-S7 (strong: level C)}

- Lung ultrasound when compared with supine chest radiography may be a better diagnostic strategy as an initial diagnostic study in critically ill patients with suspected pneumothorax, and may lead to better patient outcome.

\section{B-D1-S8 (no consensus: level C)}

- Lung ultrasound compares well with computerized tomography in assessment of pneumothorax extension.

P-D1-S1 (no consensus: level C)

- Bedside lung ultrasound is a useful tool to differentiate between small and large pneumothorax, using detection of the lung point.

Comments The four sonographic signs useful to diagnose pneumothorax and their usefulness in ruling in and ruling out the condition are reported in Fig. 1 [5]. Lung sliding is the depiction of a regular rhythmic 


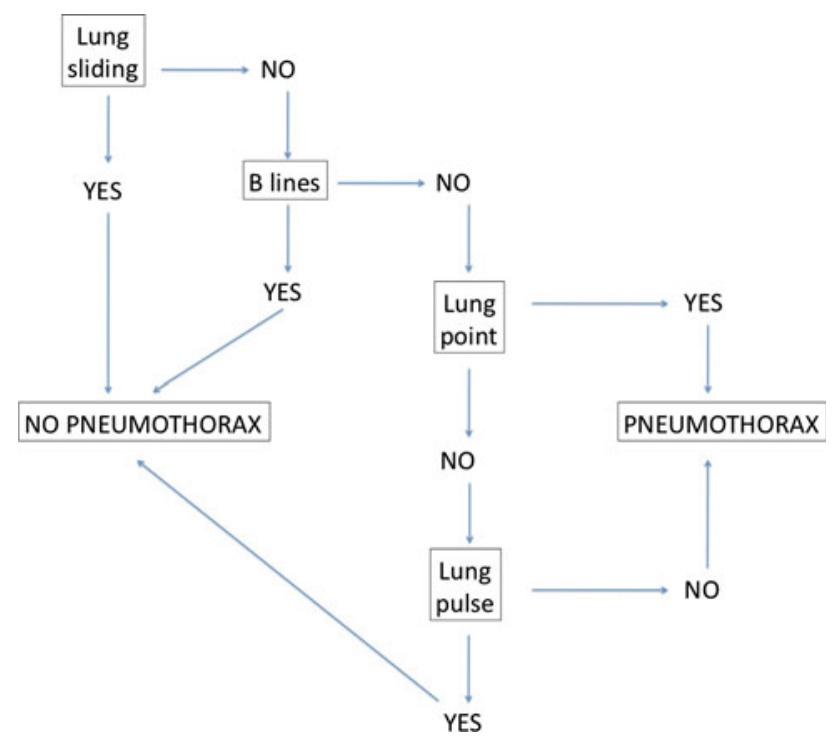

Fig. 1 Flow chart on diagnosing pneumothorax. This flow chart suggests the correct sequence and combination of the four sonographic signs useful to rule out or rule in pneumothorax

movement synchronized with respiration that occurs between the parietal and visceral pleura that are either in direct apposition or separated by a thin layer of intrapleural fluid [6-9]. The lung pulse refers to the subtle rhythmic movement of the visceral upon the parietal pleura with cardiac oscillations $[6,8,10]$. As B-lines (well defined elsewhere) originate from the visceral pleura, their simple presence proves that the visceral pleura is opposing the parietal, thus excluding pneumothorax at that point. The lung point refers to the depiction of the typical pattern of pneumothorax, which is simply the absence of any sliding or moving B-lines at a physical location where this pattern consistently transitions into an area of sliding, which represents the physical limit of pneumothorax as mapped on the chest wall [7, 11, 12].

In extreme emergency, absence of any movement of the pleural line, either horizontal (sliding) or vertical (pulse), coupled with absence of B-lines allows prompt and safe diagnosis of pneumothorax without the need for searching the lung point.

Lung ultrasound is more accurate than CXR particularly in ruling out pneumothorax [1, 6, 13-17]. There are some settings where lung ultrasound for pneumothorax is not only recommended but also essential: cardiac arrest/ unstable patient, radio-occult pneumothorax, and limitedresource areas.

Disagreement on the steep learning curve of the technique is based on the fact that the positive predictive value of ultrasound and its specificity have tended to be slightly lower than the sensitivity in the studies on pneumothorax. Consideration has been made that diagnosis of pneumothorax can require more nuanced interpretation of the combination of findings as lung bullae, contusions, adhesions, and others that can result in false positives.

Interstitial syndrome

Artifacts and physics

P-D2-S1 [strong: level not applicable (N/A)]

- B-lines are defined as discrete laser-like vertical hyperechoic reverberation artifacts that arise from the pleural line (previously described as "comet tails"), extend to the bottom of the screen without fading, and move synchronously with lung sliding.

RL-D5-S1 (strong: level N/A)

- B-lines are artifacts.

RL-D5-S2 (strong: level N/A)

- The anatomic and physical basis of B-lines is not known with certainty at this time.

B-D2-S9 (strong: level N/A)

- The term "sliding" (rather than "gliding") should be used in the description of pleural movement.

\section{Scanning and training methodology}

B-D2-S1 (strong: level A)

- Multiple B-lines are the sonographic sign of lung interstitial syndrome.

B-D2-S2 (strong: level A)

- In the evaluation of interstitial syndrome, the sonographic technique ideally consists of scanning eight regions, but two other methods have been described:

- A more rapid anterior two-region scan may be sufficient in some cases.

- The evaluation of 28 rib interspaces is an alternative.

- A positive region is defined by the presence of three or more B-lines in a longitudinal plane between two ribs.

B-D2-S4 (strong: level B)

- In the evaluation of interstitial syndrome, the following suggest a positive exam:

- Two or more positive regions (see B-D2-S2) bilaterally.

- The 28 rib space technique may semiquantify the interstitial syndrome: in each rib space, count the 
number of B-lines from zero to ten, or if confluent, assess the percentage of the rib space occupied by B-lines and divide it by ten.

\section{B-D2-S10 (strong: level N/A)}

- The term "B-pattern" should be used (rather than "lung rockets" or "B-PLUS") in the description of multiple B-lines in patients with interstitial syndrome.

\section{B-D2-S3 (strong: level B)}

- In the evaluation of interstitial syndrome, lung ultrasound should be considered as a basic technique with a steep learning curve.

\section{Clinical implications}

\section{P-D5-S1 (strong: level B)}

- The presence of multiple diffuse bilateral B-lines indicates interstitial syndrome. Causes of interstitial syndrome include the following conditions:

- Pulmonary edema of various causes

- Interstitial pneumonia or pneumonitis

- Diffuse parenchymal lung disease (pulmonary fibrosis)

P-D2-S2 (strong: level B)

- Regarding B-lines, focal multiple B-lines may be present in a normal lung, and a focal (localized) sonographic pattern of interstitial syndrome may be seen in the presence of any of the following:

- Pneumonia and pneumonitis

- Atelectasis

- Pulmonary contusion

- Pulmonary infarction

- Pleural disease

- Neoplasia

\section{RL-D3-S1 (strong: level B)}

- Lung ultrasound is a reliable tool to evaluate diffuse parenchymal lung disease (pulmonary fibrosis).

- The primary sonographic sign to be identified is the presence of multiple B-lines in a diffuse and nonhomogeneous distribution.

- Pleural line abnormalities are often present.

RL-D3-S2 (strong: level B)

- In patients with diffuse parenchymal lung disease (pulmonary fibrosis), the distribution of B-lines correlates with computed tomography (CT) signs of fibrosis.

RL-D3-S3 (strong: level B)

- In contrast to cardiogenic pulmonary edema, the sonographic findings that are indicative of diffuse parenchymal lung disease (pulmonary fibrosis) include the following:

- Pleural line abnormalities (irregular, fragmented pleural line)

- Subpleural abnormalities (small echo-poor areas)

- B-lines in a nonhomogeneous distribution

RL-D3-S4 (strong: level B)

- In contrast to cardiogenic pulmonary edema, the sonographic findings that are indicative of acute respiratory distress syndrome (ARDS) include the following:

- Anterior subpleural consolidations

- Absence or reduction of lung sliding

- "Spared areas" of normal parenchyma

- Pleural line abnormalities (irregular thickened fragmented pleural line)

- Nonhomogeneous distribution of B-lines

\section{Imaging strategies}

\section{B-D2-S5 (strong: level B)}

- Lung ultrasound is superior to conventional chest radiography for ruling in significant interstitial syndrome.

B-D2-S6 (strong: level B)

- In patients with suspected interstitial syndrome, a negative lung ultrasound examination is superior to

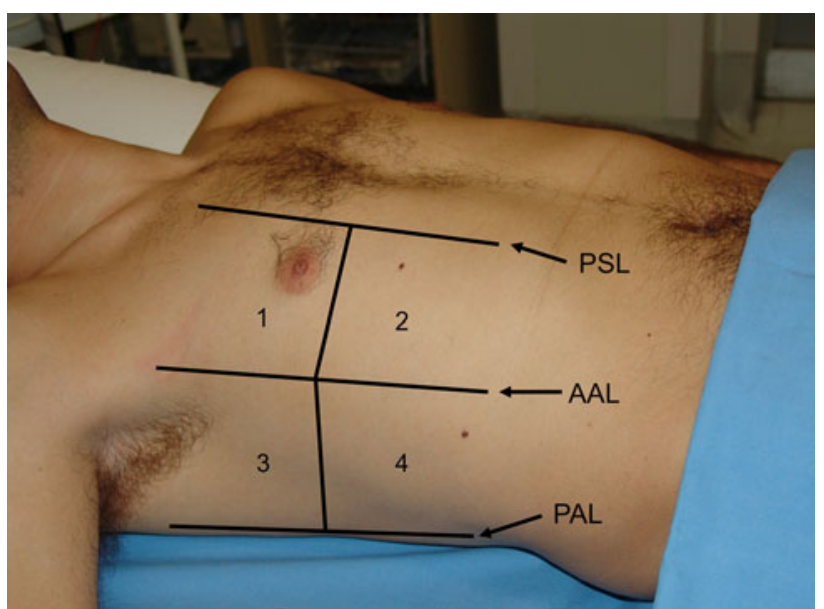

Fig. 2 The four chest areas per side considered for complete eightzone lung ultrasound examination. These areas are used to evaluate for the presence of interstitial syndrome. Areas 1 and 2 denote the upper anterior and lower anterior chest areas, respectively. Areas 3 and 4 denote the upper lateral and basal lateral chest areas, respectively. $P S L$ parasternal line, $A A L$ anterior axillary line, $P A L$ posterior axillary line (modified from Volpicelli et al. [19]) 
conventional chest radiography in ruling out significant interstitial syndrome.

B-D2-S7 (no consensus: level C)

- Lung ultrasound used as a first-line diagnostic approach in the evaluation of suspected interstitial syndrome, when compared with chest radiography, may lead to better patient outcomes.

P-D2-S3 (strong: level B)

- In resource-limited settings, lung ultrasound should be considered as a particularly useful diagnostic modality in the evaluation of interstitial syndrome.

\section{Outcomes}

\section{B-D2-S8 (strong: level C)}

- Use of sonography in diagnosis of interstitial syndrome is likely to improve the care of patients in whom this diagnosis is a consideration.

\section{B-D4-S5 (strong: level B)}

- In suspected decompensated left-sided heart failure, lung ultrasound should be considered because, with other bedside tests, it provides additional diagnostic information about this condition.

Comments Many studies showed a tight correlation between interstitial involvement of lung diseases and B-lines [10, 18-20]. The consensus process defined the basic eight-region sonographic technique (Fig. 2) and the criteria for positive scan and positive examination [1921]. In the critically ill, a more rapid anterior two-region scan may be sufficient to rule out interstitial syndrome in cardiogenic acute pulmonary edema [12]. A positive examination for sonographic diffuse interstitial syndrome allows bedside distinction between a cardiogenic versus a respiratory cause of acute dyspnea [22-24]. For more precise quantification of interstitial syndrome, the 28 -scanning-site technique can be useful, especially in cardiology and nephrology settings [25]. In acute decompensated heart failure, semiquantification of the severity of congestion can be calculated by counting the total number of B-lines (28-scanning-site technique) or the number of positive scans (eight-region technique) [26, 27]. A focal sonographic pattern of interstitial syndrome should be differentiated from a diffuse interstitial syndrome [21]. Similar B-patterns are observed in many acute and chronic conditions with diffuse interstitial involvement [1, 19, 20, 25, 28, 29]. However, some sonographic signs other than B-lines are useful to differentiate the B-pattern of cardiogenic pulmonary edema, ARDS, and pulmonary fibrosis [10]. The sonographic technique for diagnosis of interstitial syndrome is a basic technique [30-32] with superiority over conventional CXR [33].
Lung consolidation

\section{Signs and clinical implications}

B-D3-S1 (strong: level C) (this statement combines statements P-D3-S4 and P-D3-S5)

- The sonographic sign of lung consolidation is a subpleural echo-poor region or one with tissue-like echotexture.

- Lung consolidations may have a variety of causes including infection, pulmonary embolism, lung cancer and metastasis, compression atelectasis, obstructive atelectasis, and lung contusion. Additional sonographic signs that may help to determine the cause of lung consolidation include the following:

- The quality of the deep margins of the consolidation

- The presence of comet-tail reverberation artifacts at the far-field margin

- The presence of air bronchogram(s)

- The presence of fluid bronchogram(s)

- The vascular pattern within the consolidation.

B-D3-S4 (strong: level A)

- Lung ultrasound for detection of lung consolidation can be used in any clinical setting including point-ofcare examination.

\section{B-D3-S8 (strong: level A)}

- Lung ultrasound should be used in the evaluation of lung consolidation because it can differentiate consolidations due to pulmonary embolism, pneumonia, or atelectasis.

\section{P-D3-S6 (strong: level B)}

- Lung ultrasound is a clinically useful diagnostic tool in patients with suspected pulmonary embolism.

P-D3-S7 (strong: level A)

- Lung ultrasound is an alternative diagnostic tool to computerized tomography in diagnosis of pulmonary embolism when CT is contraindicated or unavailable.

\section{P-D3-S3 (strong: level B)}

- Lung ultrasound is a clinically useful tool to rule in pneumonia; however, lung ultrasound does not rule out consolidations that do not reach the pleura.

B-D4-S8 (strong: level C)

- Lower-frequency ultrasound scanning may allow for better evaluation of the extent of a consolidation.

\section{Imaging strategies and learning curve}

B-D3-S5 (strong: level A) 
- Lung ultrasound should be considered as an accurate tool in ruling in lung consolidation when compared with chest radiography.

B-D3-S6 (strong: level B)

- Lung ultrasound may be considered as an accurate tool in ruling out lung consolidation in comparison with chest radiography.

B-D3-S7 (no consensus: level C)

- Use of lung ultrasound as an initial diagnostic strategy in the evaluation of lung consolidation improves outcomes in comparison with chest radiography.

B-D3-S3 (strong: level N/A)

- Ultrasound diagnosis of lung consolidation may be considered as a basic sonographic technique with a steep learning curve.

B-D4-S6 (strong: level B)

- Lung ultrasound should be considered in the detection of radio-occult pulmonary conditions in patients with pleuritic pain.

B-D3-S2 (weak: level C)

- In the evaluation of lung consolidation, the sonographic technique should commence with the examination of areas of interest (if present, e.g., area of pain) then progress to the entire lung, as needed.

B-D4-S3 (strong: level A)

- In mechanically ventilated patients, lung ultrasound should be considered because it is more accurate than chest radiography in distinguishing various types of consolidations.

B-D4-S4 (strong: level A)

- In mechanically ventilated patients lung ultrasound should be considered as it is more accurate than portable chest radiography in the detection of consolidation.

B-D4-S9 (no consensus: level N/A)

- Lung ultrasound is accurate in distinguishing various types of consolidations in comparison with CT scan in mechanically ventilated patients.

Comments The consolidated region of the lung is visualized at lung ultrasound as an echo-poor or tissuelike image, depending on the extent of air loss and fluid predominance, which is clearly different from the normal pattern [34-38]. The cause of lung consolidation can be diagnosed by analyzing the sonographic features of the lesion [39, 40]. Accuracy of lung ultrasound in the diagnosis and differential diagnosis of lung consolidation has been tested in different settings [36, 41-44] and showed good accuracy compared with CXR [43, 45-48]. In pleuritic pain, lung ultrasound is superior to CXR and may allow visualization of radio-occult pulmonary conditions [47, 48]. In mechanically ventilated patients, lung ultrasound is more accurate than CXR in detecting and distinguishing various types of consolidations $[49,50]$.

Monitoring lung diseases

B-D4-S1 (strong: level A)

- In patients with cardiogenic pulmonary edema, semiquantification of disease severity may be obtained by evaluating the number of B-lines as this is directly proportional to the severity of congestion.

B-D4-S2 (strong: level A)

- In patients with cardiogenic pulmonary edema, B-lines should be evaluated because it allows monitoring of response to therapy.

P-D3-S1 (strong: level A)

- In patients with increased extravascular lung water, assessment of lung reaeration can be assessed by demonstrating a change (decrease) in the number of B-lines.

P-D3-S2 (strong: level A)

- In the majority of cases of acute lung injury or ARDS, ultrasound quantification of lung reaeration may be assessed by tracking changes in sonographic findings.

- Sonographic findings should include assessment of lung consolidation and B-lines.

RL-D2-S1 (strong: level A)

- In critically ill patients with acute lung injury or ARDS, ultrasound changes in lung aeration can be semiquantitatively assessed (at a given location on the chest) using the following four sonographic findings, often in progression:

- Normal pattern

- Multiple spaced B-lines

- Coalescent B-lines

- Consolidation

RL-D2-S2 (strong: level A)

- Lung ultrasound is able to monitor aeration changes and the effects of therapy in a number of acute lung diseases, including the following:

- Acute pulmonary edema

- Acute respiratory distress syndrome

- Acute lung injury

- Community-acquired pneumonia

- Ventilator-associated pneumonia 
- Recovery from lavage of alveolar proteinosis

RL-D3-S5 (strong: level B)

- Serial evaluation of B-lines allows monitoring of pulmonary congestion in patients on hemodialysis, but is of undetermined clinical utility.

P-D2-S4 (no consensus: level C)

- The semiquantitative techniques of B-line evaluation (see B-D2-S2 and B-D2-S4) are useful as a prognostic indicator of outcomes or mortality in patients with left-sided heart failure.

\section{RL-D6-S1 (strong: level B)}

- Semiquantitative B-line assessment is a prognostic indicator of adverse outcomes and mortality in patients with acute decompensated heart failure.

Comments The concept of using lung ultrasound for monitoring the patient is one of the major innovations that emerged from recent studies. Pulmonary congestion may be semiquantified using lung ultrasound $[22,25,27,51-$ 55]. In the clinical arena, lung ultrasound can therefore be employed as a bedside, easy-to-use, alternative tool for monitoring pulmonary congestion changes in heart failure patients, as they disappear or clear upon adequate medical treatment [27, 56-60]. More generally, any significant change in lung aeration resulting from any therapy aimed at reversing aeration loss might be detected by corresponding changes in lung ultrasound patterns [61, 62].

Neonatology and pediatrics

P-D4-S1 (strong: level B)

- Lung ultrasound is a clinically useful diagnostic tool in neonates with suspected respiratory distress syndrome (RDS).

P-D4-S2 (strong: level B)

- All the following sonographic signs are likely to be present in neonates with respiratory distress syndrome:

- Pleural line abnormalities

- Absence of spared areas

- Bilateral confluent B-lines

P-D4-S3 (strong: level B)

- Lung ultrasound is as accurate as chest radiography in the diagnosis of respiratory distress syndrome in neonates.

P-D4-S4 (strong: level B)

- Lung ultrasound is a clinically useful diagnostic tool in suspected transient tachypnea of the newborn (TTN).
P-D4-S5 (strong: level B)

- The sonographic signs for transient tachypnea of the newborn are bilateral confluent B-lines in the dependent areas of the lung ("white lung") and normal or near-normal appearance of the lung in the superior fields.

P-D4-S6 (strong: level B)

- Lung ultrasound is as accurate as chest radiography in diagnosis of TTN.

P-D4-S7 (strong: level B)

- Lung ultrasound is a clinically useful diagnostic tool in pediatric patients with suspected pneumonia.

P-D4-S8 (strong: level A)

- The ultrasound signs of lung and pleural diseases described in adults are also found in pediatric patients.

P-D4-S9 (strong: level A)

- Lung ultrasound is as accurate as chest radiography in diagnosis of pneumonia in pediatric patients.

Comments In newborns, lung ultrasound signs are similar to those previously described in adults, although these signs will be context specific. Lung ultrasound allows diagnosis of RDS with accuracy similar to CXR even if there is no correlation between the different radiographic stages of RDS and ultrasound findings [63]. Lung ultrasound demonstrates very unique findings in the diagnosis of TTN, whereas CXR is nonspecific [64].

Many studies showed that the ultrasound signs of lung and pleural diseases described in adults are also found in pediatric patients [45, 65-68]. In suspected pneumonia, lung ultrasound has demonstrated to be no less accurate than CXR. These data suggest that, when there is clinical suspicion of pneumonia, a positive lung ultrasound excludes the need to perform CXR.

\section{Pleural effusion}

\section{RL-D4-S3 (strong: level A)}

- Both of the following signs are present in almost all free effusions:

- A space (usually anechoic) between the parietal and visceral pleura

- Respiratory movement of the lung within the effusion ("sinusoid sign")

RL-D4-S5 (strong: level A)

- A pleural effusion with internal echoes suggests that it is an exudate or hemorrhage. While most transudates are anechoic, some exudates are also anechoic. Thoracentesis may be needed for further characterization. 
RL-D4-S1 (strong: level B)

- In the evaluation of pleural effusion in adults, the microconvex transducer is preferable. If not available, a phased array or a convex transducer can be used.

RL-D4-S2 (strong: level B)

- The optimal site to detect a nonloculated pleural effusion is at the posterior axillary line above the diaphragm.

RL-D4-S4 (strong: level A)

- For the detection of effusion, lung ultrasound is more accurate than supine radiography and is as accurate as CT.

B-D4-S7 (strong: level A)

- In opacities identified by chest radiography, lung ultrasound should be used because it is more accurate than chest radiography in distinguishing between effusion and consolidation.

Comments Pleural effusion is usually visualized as an anechoic space between the parietal and visceral pleura. This condition can be obvious in patients with substantial effusion. In other conditions, such as complex effusion and in patients where pleural effusion is suspected, the sonographic technique can benefit from standardized criteria to improve diagnostic accuracy. The sinusoid sign is a dynamic sign showing the variation of the interpleural distance during the respiratory cycles $[69,70]$. This variation is easily visualized on M-mode as a sinusoid movement of the visceral pleura [70].

Lung ultrasound has the potential also for diagnosing the nature of the effusion [71]. Visualization of internal echoes, either of mobile particles or septa, is highly suggestive of exudate or hemothorax [72-76]. However, when faced with an anechoic effusion, the only way to differentiate between transudate and exudate is to use thoracentesis or alternatively to evaluate effusion in the clinical context [71, 77-79].

Lung ultrasound accuracy is proved to be higher than CXR, particularly when anterior-posterior view in the supine patient is considered $[49,69,70]$. Lung ultrasound performance is nearly as good as CT scan $[49,80]$.

Update plan

New research and knowledge will give impetus to update these guidelines by renewing the development process at least every 4 years or whenever a significant major change in evidence appears. A professional librarian will review literature on a regular basis and send any updates to the corresponding author. The panel is open to new inputs, and the position of new researchers and experts will be considered in the future before the next revision.

\section{Conclusions}

This is the first document reporting evidence-based recommendations on clinical use of point-of-care lung ultrasound. Experts who published the vast majority of papers on clinical use of lung ultrasound in the last 20 years elaborated these specific 73 recommendations. A number of these recommendations will potentially reshape the future practice and knowledge of this rapidly expanding field. These applications will benefit patients worldwide as rigorous assessment, classification, and publication efforts continue to make this critical information available to all clinicians. The advantages of correct use of bedside lung ultrasound in the emergency setting are striking, particularly in terms of saving from radiation exposure, delaying or even avoiding transportation to the radiology suite, and guiding life-saving therapies in extreme emergency. This document was elaborated to guide implementation, development, and training on use of lung ultrasound in all relevant settings; it will also serve as the basis for further research and to influence and enhance the associated standards of care.

\section{Appendix}

Organizing society

World Interactive Network Focused on Critical Ultrasound (WINFOCUS)

Consensus conference participants and affiliations

Working subgroup leaders

Writing committee: G Volpicelli (Emergency Medicine, San Luigi Gonzaga University Hospital, Torino, Italy)

Document reviewers: M Blaivas (Department of Emergency Medicine, Northside Hospital Forsyth, Atlanta, GA, USA)

Methodology committee: M Elbarbary (National \& Gulf Center for Evidence Based Health Practice, King Saud University for Health Sciences, Riyadh, Saudi Arabia)

Organizing committee: L Neri (AREU EMS Public Regional Company, Niguarda Ca' Granda Hospital, Milano, Italy)

\section{Working committees}

Writing committee:

- DA Lichtenstein (Service de Réanimation Médicale, Hôpital Ambroise-Paré, Boulogne, Paris-Ouest, France) 
- G Mathis (Internal Medicine Praxis, Rankweil, Austria)

- A Kirkpatrick (Foothills Medical Centre, Calgary, AB, Canada)

- L Gargani (Institute of Clinical Physiology, National Research Council, Pisa, Italy)

- VE Noble (Division of Emergency Ultrasound, Department of Emergency Medicine, Massachusetts General Hospital, Boston, MA, USA)

- R Copetti (Medical Department, Latisana Hospital, Udine, Italy)

- G Soldati (Emergency Medicine Unit, Valle del Serchio General Hospital, Lucca, Italy)

- B Bouhemad (Surgical Intensive Care Unit, Department of Anesthesia and Critical Care, Groupe Hospitalier Paris Saint-Joseph, Paris, France)

- A Reissig (Department of Pneumology and Allergology, Medical University Clinic I, Friedrich-Schiller University, Jena, Germany)

- JJ Rouby (Multidisciplinary Intensive Care Unit, Department of Anesthesiology, Pitié-Salpêtrière Hospital, University Pierre and Marie Curie, Paris, France)

Document reviewers:

- G Via (IRCCS Foundation Policlinico San Matteo, Pavia, Italy)

- E Agricola (Division of Noninvasive Cardiology, San Raffaele Scientific Institute, IRCCS, Milan, Italy)

- JW Tsung (Mount Sinai School of Medicine, Departments of Emergency Medicine and Pediatrics, New York, NY, USA)

Methodology committee:

- L Melniker (Department of Emergency Medicine, New York Methodist Hospital and Clinical Epidemiology Unit, Division of General Internal Medicine, Department of Medicine, Weill Medical College of Cornell University, NY, USA)
- A Dean (Division of Emergency Ultrasonography, Department of Emergency Medicine, University of Pennsylvania Medical Center, Philadelphia, PA, USA)

- R Breitkreutz [Department of Anaesthesiology, Intensive Care and Pain therapy, University Hospital of the Saarland and Frankfurt Institute of Emergency Medicine and Simulation Training (FINEST), Germany]

- A Seibel (Diakonie Klinikum jung-stilling, Siegen, Germany)

Organizing committee:

- E Storti (Intensive Care Unit "G. Bozza," Niguarda Ca' Granda Hospital, Milan, Italy)

- T Petrovic (Samu 93, University Hospital Avicenne, Bobigny, France)

Other consensus conference members:

- C Arbelot (Multidisciplinary Intensive Care Unit, Department of Anesthesiology, Pitié-Salpêtrière Hospital, University Pierre and Marie Curie, Paris, France)

- A Liteplo (Emergency Medicine, Massachusetts General Hospital, Boston, MA, USA)

- A Sargsyan (Wyle/NASA Lyndon B. Johnson Space Center Bioastronautics Contract, Houston, TX, USA)

- F Silva (UC Davis Medical Center, Emergency Medicine, Sacramento, CA, USA)

- R Hoppmann (Internal Medicine, University of South Carolina School of Medicine)

Acknowledgments Special thanks to the Cornell library staff for conducting the literature search, to Ms. Maddalena Bracchetti for her outstanding organizational and administrative support, and to all the secretariat staff. This study was endorsed by the World Interactive Network Focused on Critical Ultrasound (WINFOCUS).

Conflicts of interest The authors declare that they have no competing interests.

\section{References}

1. Elbarbary M, Melniker LA, Volpicelli G, Neri L, Petrovic T, Storti E, Blaivas M (2010) Development of evidencebased clinical recommendations and consensus statements in critical ultrasound field: why and how? Crit Ultrasound J 2:93-95

2. Guyatt GH, Oxman AD, Schunemann HJ, Tugwell P, Knottnerus A (2011) GRADE guidelines: a new series of articles in the Journal of Clinical Epidemiology. J Clin Epidemiol 64:380-382
3. Fitch K, Bernstein SJ, Aguilar MD, Burnand B, LaCalle JR, Lazaro P, van het Loo M, McDonnell J, Vader JP, Kahan JP (2001) The RAND/UCLA appropriateness method user's manual. RAND Corporation, Arlington

4. Baumann MH, Strange C, Heffner JE, Light R, Kirby TJ, Klein J, Luketich JD, Panacek EA, Sahn SA (2001)

Management of spontaneous pneumothorax: an American College of Chest Physicians Delphi consensus statement. Chest 119:590-602

5. Volpicelli G (2011) Sonographic diagnosis of pneumothorax. Intensive Care Med 37:224-232
6. Kirkpatrick AW, Sirois M, Laupland KB, Liu D, Rowan K, Ball CG, Hameed SM, Brown R, Simons R, Dulchavsky SA, Hamiilton DR, Nicolaou S (2004) Hand-held thoracic sonography for detecting post-traumatic pneumothoraces: the extended focused assessment with sonography for trauma (EFAST). J Trauma 57:288-295

7. Lichtenstein D, Meziere G, Biderman P, Gepner A (2000) The "lung point": an ultrasound sign specific to pneumothorax. Intensive Care Med 26:1434-1440 
8. Lichtenstein DA, Lascols N, Prin S, Meziere G (2003) The "lung pulse": an early ultrasound sign of complete atelectasis. Intensive Care Med 29:2187-2192

9. Lichtenstein DA, Menu Y (1995) A bedside ultrasound sign ruling out pneumothorax in the critically ill. Lung sliding. Chest 108:1345-1348

10. Copetti R, Soldati G, Copetti P (2008) Chest sonography: a useful tool to differentiate acute cardiogenic pulmonary edema from acute respiratory distress syndrome. Cardiovase Ultrasound 6:16

11. Gillman LM, Alkadi A, Kirkpatrick AW (2009) The "pseudo-lung point" sign: all focal respiratory coupled alternating pleural patterns are not diagnostic of a pneumothorax. J Trauma 67:672-673

12. Lichtenstein DA, Meziere GA (2008) Relevance of lung ultrasound in the diagnosis of acute respiratory failure: the BLUE protocol. Chest 134:117-125

13. Blaivas M, Lyon M, Duggal S (2005) A prospective comparison of supine chest radiography and bedside ultrasound for the diagnosis of traumatic pneumothorax. Acad Emerg Med 12:844-849

14. Rowan KR, Kirkpatrick AW, Liu D, Forkheim KE, Mayo JR, Nicolaou S (2002) Traumatic pneumothorax detection with thoracic US: correlation with chest radiography and CT-initial experience. Radiology 225:210-214

15. Soldati G, Testa A, Pignataro G, Portale G, Biasucci DG, Leone A, Silveri NG (2006) The ultrasonographic deep sulcus sign in traumatic pneumothorax. Ultrasound Med Biol 32:1157-1163

16. Soldati G, Testa A, Sher S, Pignataro G, La Sala M, Silveri NG (2008) Occult traumatic pneumothorax: diagnostic accuracy of lung ultrasonography in the emergency department. Chest 133:204-211

17. Zhang M, Liu ZH, Yang JX, Gan JX, Xu SW, You XD, Jiang GY (2006) Rapid detection of pneumothorax by ultrasonography in patients with multiple trauma. Crit Care 10:R112

18. Soldati G, Testa A, Silva FR, Carbone L, Portale G, Silveri NG (2006) Chest ultrasonography in lung contusion. Chest 130:533-538

19. Volpicelli G, Mussa A, Garofalo G, Cardinale L, Casoli G, Perotto F, Fava C, Frascisco M (2006) Bedside lung ultrasound in the assessment of alveolar-interstitial syndrome. Am J Emerg Med 24:689-696
20. Lichtenstein D, Meziere G, Biderman P, Gepner A, Barre O (1997) The comet-tail artifact. An ultrasound sign of alveolar-interstitial syndrome. Am J Respir Crit Care Med 156:1640-1646

21. Volpicelli G, Caramello V, Cardinale L, Mussa A, Bar F, Frascisco MF (2008) Detection of sonographic B-lines in patients with normal lung or radiographic alveolar consolidation. Med Sci Monit 14:CR122-CR128

22. Gargani L, Frassi F, Soldati G, Tesorio P, Gheorghiade M, Picano E (2008) Ultrasound lung comets for the differential diagnosis of acute cardiogenic dyspnoea: a comparison with natriuretic peptides. Eur J Heart Fail 10:70-77

23. Liteplo AS, Marill KA, Villen T, Miller RM, Murray AF, Croft PE, Capp R, Noble VE (2009) Emergency thoracic ultrasound in the differentiation of the etiology of shortness of breath (ETUDES): sonographic B-lines and $\mathrm{N}$-terminal pro-brain-type natriuretic peptide in diagnosing congestive heart failure. Acad Emerg Med 16:201-210

24. Volpicelli G, Cardinale L, Garofalo G, Veltri A (2008) Usefulness of lung ultrasound in the bedside distinction between pulmonary edema and exacerbation of COPD. Emerg Radiol 15:145-151

25. Jambrik Z, Monti S, Coppola V, Agricola E, Mottola G, Miniati M, Picano E (2004) Usefulness of ultrasound lung comets as a nonradiologic sign of extravascular lung water. Am J Cardiol 93:1265-1270

26. Picano E, Frassi F, Agricola E, Gligorova S, Gargani L, Mottola G (2006) Ultrasound lung comets: a clinically useful sign of extravascular lung water. J Am Soc Echocardiogr 19:356-363

27. Volpicelli G, Caramello V, Cardinale L, Mussa A, Bar F, Frascisco MF (2008) Bedside ultrasound of the lung for the monitoring of acute decompensated heart failure. Am J Emerg Med 26:585-591

28. Reissig A, Kroegel C (2003) Transthoracic sonography of diffuse parenchymal lung disease: the role of comet tail artifacts. J Ultrasound Med 22:173-180

29. Soldati G, Copetti R, Sher S (2009) Sonographic interstitial syndrome: the sound of lung water. J Ultrasound Med 28:163-174

30. Bedetti G, Gargani L, Corbisiero A, Frassi F, Poggianti E, Mottola G (2006) Evaluation of ultrasound lung comets by hand-held echocardiography. Cardiovasc Ultrasound 4:34
31. Noble VE, Lamhaut L, Capp R, Bosson N, Liteplo A, Marx JS, Carli P (2009) Evaluation of a thoracic ultrasound training module for the detection of pneumothorax and pulmonary edema by prehospital physician care providers. BMC Med Educ 9:3

32. Sicari R, Galderisi M, Voigt JU, Habib G, Zamorano JL, Lancellotti P, Badano LP (2011) The use of pocket-size imaging devices: a position statement of the European Association of Echocardiography. Eur J Echocardiogr 12:85-87

33. Zanobetti M, Poggioni C, Pini R (2011) Can chest ultrasonography replace standard chest radiography for evaluation of acute dyspnea in the ED? Chest 139:1140-1147

34. Arbelot C, Ferrari F, Bouhemad B, Rouby JJ (2008) Lung ultrasound in acute respiratory distress syndrome and acute lung injury. Curr Opin Crit Care 14:70-74

35. Bouhemad B, Zhang M, Lu Q, Rouby JJ (2007) Clinical review: bedside lung ultrasound in critical care practice. Crit Care 11:205

36. Gehmacher O, Mathis G, Kopf A, Scheier M (1995) Ultrasound imaging of pneumonia. Ultrasound Med Biol 21:1119-1122

37. Lichtenstein DA (2007) Ultrasound in the management of thoracic disease. Crit Care Med 35:S250-S261

38. Volpicelli G, Silva F, Radeos M (2010) Real-time lung ultrasound for the diagnosis of alveolar consolidation and interstitial syndrome in the emergency department. Eur J Emerg Med 17:63-72

39. Lichtenstein D, Meziere G, Seitz J (2009) The dynamic air bronchogram. A lung ultrasound sign of alveolar consolidation ruling out atelectasis. Chest 135:1421-1425

40. Reissig A, Kroegel C (2003) Transthoracic ultrasound of lung and pleura in the diagnosis of pulmonary embolism: a novel non-invasive bedside approach. Respiration 70:441-452

41. Lichtenstein DA, Lascols N, Meziere G, Gepner A (2004) Ultrasound diagnosis of alveolar consolidation in the critically ill. Intensive Care Med 30:276-281

42. Mathis G, Blank W, Reissig A, Lechleitner P, Reuss J, Schuler A, Beckh S (2005) Thoracic ultrasound for diagnosing pulmonary embolism: a prospective multicenter study of 352 patients. Chest 128:1531-1538

43. Parlamento S, Copetti R, Di Bartolomeo S (2009) Evaluation of lung ultrasound for the diagnosis of pneumonia in the ED. Am J Emerg Med 27:379-384 
44. Reissig A, Kroegel C (2007) Sonographic diagnosis and follow-up of pneumonia: a prospective study. Respiration 74:537-547

45. Copetti R, Cattarossi L (2008) Ultrasound diagnosis of pneumonia in children. Radiol Med 113:190-198

46. Reissig A, Mempel C, Copetti R, Groß F, Neumann R, Mathis G, Kroegel C (2010) Temporary results $(05 / 2010)$ of the multicentre DEGUM-/ÖGUMstudy: role of chest ultrasound in diagnosing and follow-up of pneumonia. Ultraschall Med 31:S65

47. Volpicelli G, Caramello V, Cardinale L, Cravino M (2008) Diagnosis of radiooccult pulmonary conditions by realtime chest ultrasonography in patients with pleuritic pain. Ultrasound Med Biol 34:1717-1723

48. Volpicelli G, Cardinale L, Berchialla P, Mussa A, Bar F, Frascisco MF (2011) A comparison of different diagnostic tests in the bedside evaluation of pleuritic pain in the ED. Am J Emerg Med. doi: 101016/jajem201011035

49. Lichtenstein D, Goldstein I, Mourgeon E, Cluzel P, Grenier P, Rouby JJ (2004) Comparative diagnostic performances of auscultation, chest radiography, and lung ultrasonography in acute respiratory distress syndrome. Anesthesiology 100:9-15

50. Peris A, Tutino L, Zagli G, Batacchi S, Cianchi G, Spina R, Bonizzoli M, Migliaccio L, Perretta L, Bartolini M, Ban K, Balik M (2010) The use of point-of-care bedside lung ultrasound significantly reduces the number of radiographs and computed tomography scans in critically ill patients. Anesth Analg 111:687-692

51. Agricola E, Bove T, Oppizzi M, Marino G, Zangrillo A, Margonato A, Picano E (2005) "Ultrasound comet-tail images": a marker of pulmonary edema: a comparative study with wedge pressure and extravascular lung water. Chest 127:1690-1695

52. Agricola E, Picano E, Oppizzi M, Pisani M, Meris A, Fragasso G, Margonato A (2006) Assessment of stress-induced pulmonary interstitial edema by chest ultrasound during exercise echocardiography and its correlation with left ventricular function. J Am Soc Echocardiogr 19:457-463

53. Fagenholz PJ, Gutman JA, Murray AF, Noble VE, Thomas SH, Harris NS (2007) Chest ultrasonography for the diagnosis and monitoring of highaltitude pulmonary edema. Chest 131:1013-1018
54. Frassi F, Gargani L, Gligorova S, Ciampi Q, Mottola G, Picano E (2007) Clinical and echocardiographic determinants of ultrasound lung comets. Eur J Echocardiogr 8:474-479

55. Via G, Lichtenstein D, Mojoli F, Rodi G, Neri L, Storti E, Klersy C, Iotti G, Braschi A (2010) Whole lung lavage: a unique model for ultrasound assessment of lung aeration changes. Intensive Care Med 36:999-1007

56. Gargani L (2011) Lung ultrasound: a new tool for the cardiologist. Cardiovasc Ultrasound 9:6

57. Liteplo AS, Murray AF, Kimberly HH, Noble VE (2010) Real-time resolution of sonographic B-lines in a patient with pulmonary edema on continuous positive airway pressure. Am J Emerg Med 28:541.e5-541.e8

58. Mallamaci F, Benedetto FA, Tripepi R, Rastelli S, Castellino P, Tripepi G, Picano E, Zoccali C (2010) Detection of pulmonary congestion by chest ultrasound in dialysis patients. JACC Cardiovasc Imaging 3:586-594

59. Noble VE, Murray AF, Capp R, SylviaReardon MH, Steele DJ, Liteplo A (2009) Ultrasound assessment for extravascular lung water in patients undergoing hemodialysis. Time course for resolution. Chest 135:1433-1439

60. Picano E, Gargani L, Gheorghiade M (2010) Why, when, and how to assess pulmonary congestion in heart failure: pathophysiological, clinical, and methodological implications. Heart Fail Rev 15:63-72

61. Bouhemad B, Brisson H, Le-Guen M, Arbelot C, Lu Q, Rouby JJ (2011) Bedside ultrasound assessment of positive end-expiratory pressureinduced lung recruitment. Am J Respir Crit Care Med 183:341-347

62. Bouhemad B, Liu ZH, Arbelot C, Zhang M, Ferarri F, Le-Guen M, Girard M, Lu Q, Rouby JJ (2010) Ultrasound assessment of antibiotic-induced pulmonary reaeration in ventilatorassociated pneumonia. Crit Care Med 38:84-92

63. Copetti R, Cattarossi L, Macagno F, Violino M, Furlan R (2008) Lung ultrasound in respiratory distress syndrome: a useful tool for early diagnosis. Neonatology 94:52-59

64. Copetti R, Cattarossi L (2007) The 'double lung point': an ultrasound sign diagnostic of transient tachypnea of the newborn. Neonatology 91:203-209
65. Coley BD (2005) Pediatric chest ultrasound. Radiol Clin North Am 43:405-418

66. Iuri D, De Candia A, Bazzocchi M (2009) Evaluation of the lung in children with suspected pneumonia: usefulness of ultrasonography. Radiol Med 114:321-330

67. Lichtenstein DA (2009) Ultrasound examination of the lungs in the intensive care unit. Pediatr Crit Care Med 10:693-698

68. Riccabona M (2008) Ultrasound of the chest in children (mediastinum excluded). Eur Radiol 18:390-399

69. Kocijancic I, Vidmar K, IvanoviHerceg Z (2003) Chest sonography versus lateral decubitus radiography in the diagnosis of small pleural effusions. J Clin Ultrasound 31:69-74

70. Lichtenstein D, Hulot JS, Rabiller A, Tostivint I, Meziere G (1999) Feasibility and safety of ultrasoundaided thoracentesis in mechanically ventilated patients. Intensive Care Med 25:955-958

71. Sajadieh H, Afzali F, Sajadieh V, Sajadieh A (2004) Ultrasound as an alternative to aspiration for determining the nature of pleural effusion, especially in older people. Ann N Y Acad Sci 1019:585-592

72. Chian CF, Su WL, Soh LH, Yan HC, Perng WC, Wu CP (2004) Echogenic swirling pattern as a predictor of malignant pleural effusions in patients with malignancies. Chest 126:129-134

73. Gorg C, Restrepo I, Schwerk WB (1997) Sonography of malignant pleural effusion. Eur Radiol 7:1195-1198

74. Qureshi NR, Rahman NM, Gleeson FV (2009) Thoracic ultrasound in the diagnosis of malignant pleural effusion. Thorax 64:139-143

75. Tu CY, Hsu WH, Hsia TC, Chen HJ, Tsai KD, Hung CW, Shih CM (2004) Pleural effusions in febrile medical ICU patients: chest ultrasound study. Chest 126:1274-1280

76. Yang PC, Luh KT, Chang DB, Wu HD, Yu CJ, Kuo SH (1992) Value of sonography in determining the nature of pleural effusion: analysis of 320 cases. AJR Am J Roentgenol 159:29-33

77. Brooks A, Davies B, Smethhurst M, Connolly J (2004) Emergency ultrasound in the acute assessment of haemothorax. Emerg Med J 21:44-46 
78. Chen HJ, Tu CY, Ling SJ, Chen W, Chiu KL, Hsia TC, Shih CM, Hsu WH (2008) Sonographic appearances in transudative pleural effusions: not always an anechoic pattern. Ultrasound Med Biol 34:362-369
79. Ma OJ, Mateer JR (1997) Trauma ultrasound examination versus chest radiography in the detection of hemothorax. Ann Emerg Med 29:312-315
80. Rocco M, Carbone I, Morelli A, Bertoletti L, Rossi S, Vitale M, Montini L, Passariello R, Pietropaoli P (2008) Diagnostic accuracy of bedside ultrasonography in the ICU: feasibility of detecting pulmonary effusion and lung contusion in patients on respiratory support after severe blunt thoracic trauma. Acta Anaesthesiol Scand 52:776-784 